\title{
الاستغناء بصيغة (فَعْلاء) عن صيغة (أفْعل) في باب الصّفة المشبّهة
}

\section{حسين عباس محمود الرفايعة}

أستاذ دكتور- قسم اللغة العربيّة وآدابها- جامعة الحسين بن طلال- الأردن drhussen948@yahoo.com 


$$
\text { المجلة الدولية للدراسات اللغوية والأدبية العربية }
$$

\title{
الاستغناء بصيغة (فَعْلاء) عن صيغة (أَفْعل) في باب الصرّفة المشبّهـة
}

\author{
حسين عباس محمود الرفايعة \\ أستاذ دكتور - قسم اللغة العربيّة وآدابها- جامعة الحسين بن طلال- الأردن \\ drhussen948@yahoo.com
}

DOI: https://doi.org/10.31559/JALLS2021.3.3.2 2021/8/16 2021/5/19 مراجعة البحث: 2021/7/13 قبول البحث: 20بحث: 2013

\section{المللخّصص:}

إنّ النمط الصّرفيّ المستعمل في الصّّفة المشبّهـة يقضي بأن تكون صيغة (فَعْلاء) رديفاً لصيغة (أفعل) في الألوان ، والعيوب،

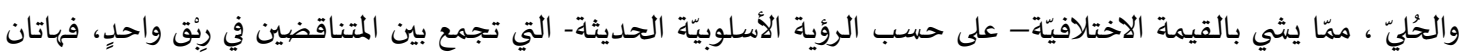

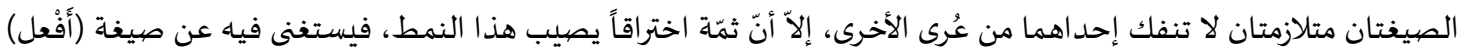

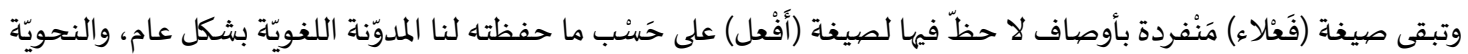

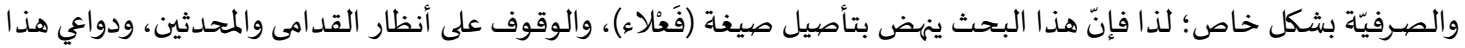

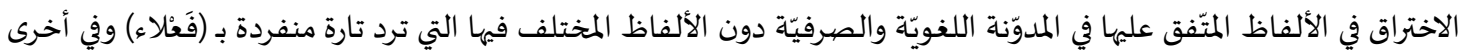

$$
\text { تأتي مشتركة بين (أَفْعل) و (فَعْلاء) . }
$$

الكلمات المفتاحيّة: النمط الصرفيّ؛ صيغة (فَعْلاء)؛ المسوّغات؛ الاستغناء.

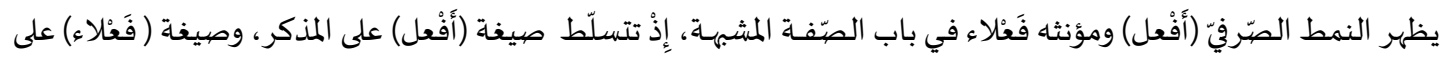

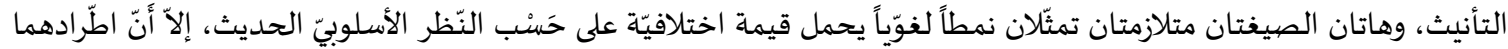

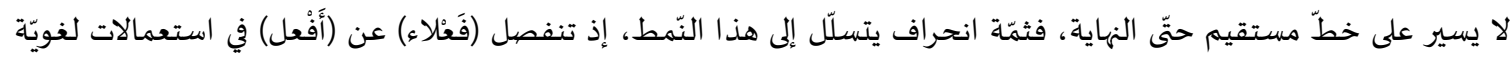

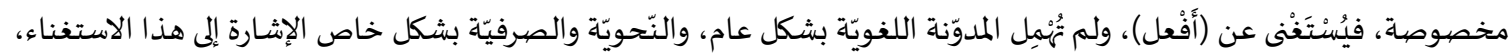

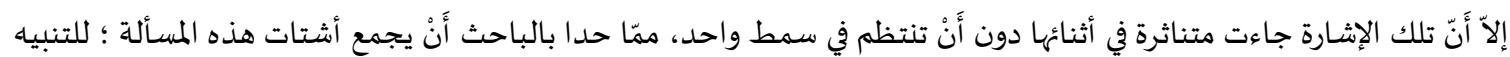

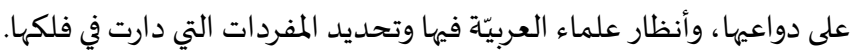

\section{المبحث الأول: صيغة فَعْلاء والتأصيل}

ثمّة إشـارة دقيقة توفّرت عليها حال التأصيل لِّ (فَعْلاء) على حسب نصّّ الثمانيني، إذ ذهب إلى أنّ أصل (فَمْلاء) المممدودة يرجع

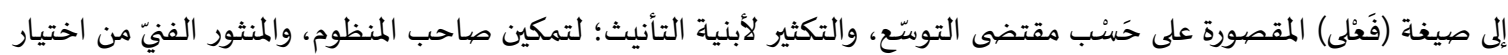

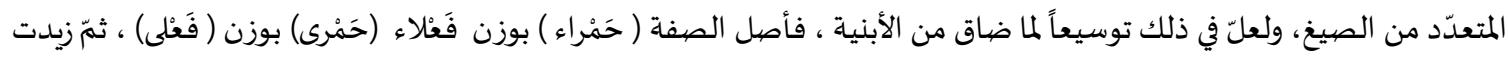

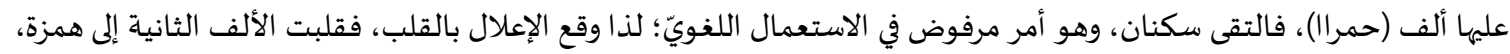

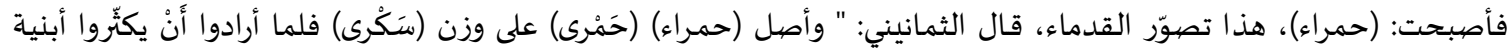

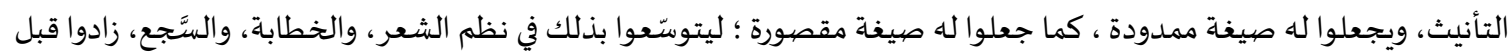
الألف التي في (حمراء) ألفاً للمدّ، فصارت ألف التأنيث طرفاً بعد ألف زائدة فاجتمعت ألفان، فلم يَخْلُ أن تجمع بينهما، أو 
يسقطوهما، أو يسقطوا إحداهما، أو يحركوا إحداهما ولا يجـوز الجمع بين ألفين لسكونها، ولا يجوز إسقاطهما؛ لئلا يختلّ معنى الاسم ..." (1)

على أَنّ هذا النّظر عند القدامى قَدْ تجدّد ذكره في أنظار المحدثين، إذْ لم يستبعد عبد الصببور شاهين أن تكون صيغة (فَعْلاء)

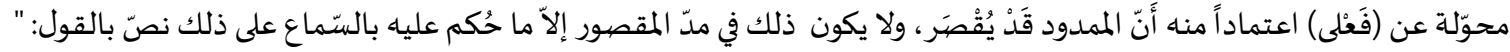

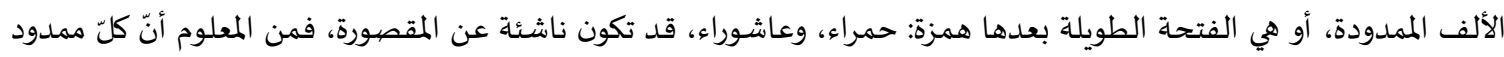

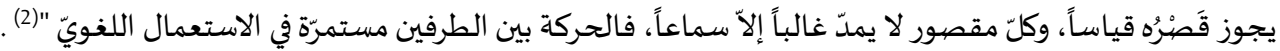

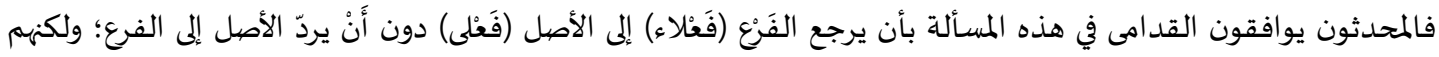

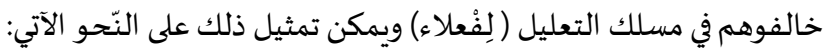
ḥamrā < ḥamrāā < ḥamrā> (الأصل ) (الفرع) مرحلة التحوّل الأخيرة مرحلة التحوّل الثانية > ردّ الفرع إلى الأصل > جائز

\section{ḥamrā $><$ ḥamrāā < ḥamrā}

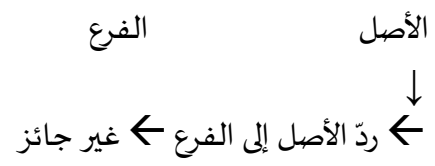

لذا فإنّ القدامى قد حملوا قول الشـاعر في ردّ الأصل إلى الفَرْع على الضرورة الشعريّة (3) (الوافر) :
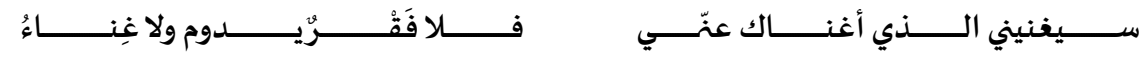

فالأصهل (غِنَى)، فَرُدَّه هذا الأصهل إلى الفَرْع ( غِناء) ليستقيم وزن البيت.

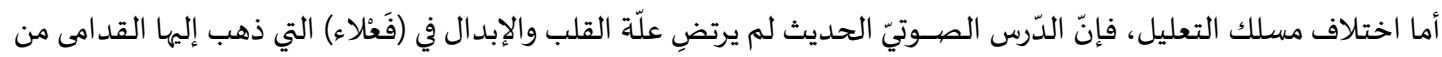

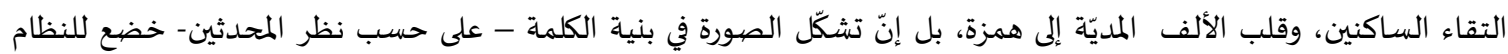

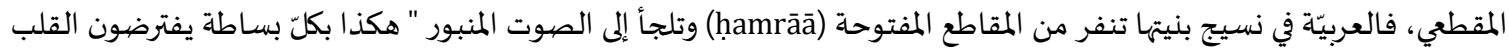

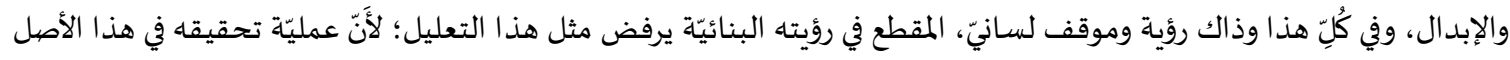

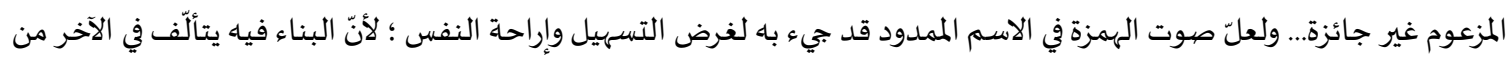

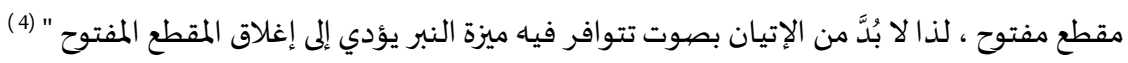

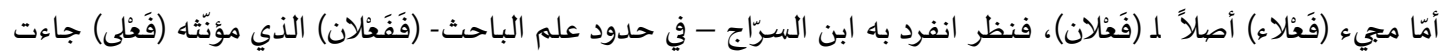

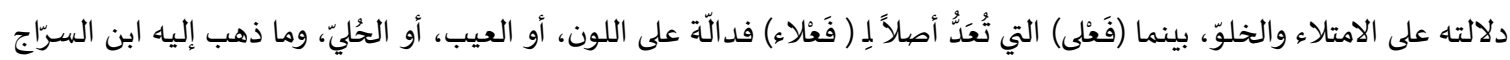

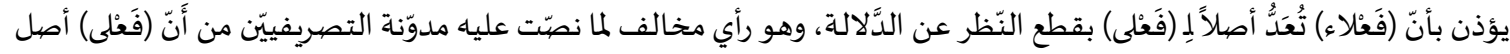

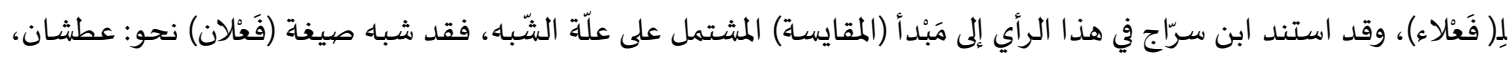

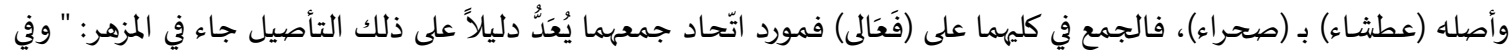

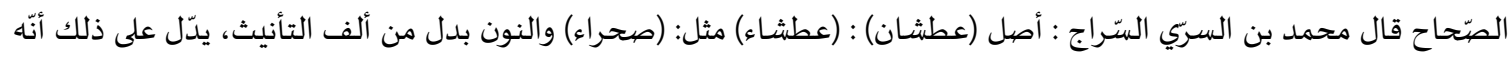

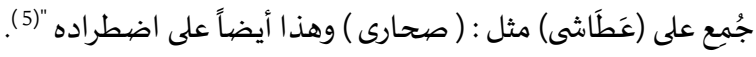
ويمكن تمثل ذلك على النّحو الآتي بالتحليل الصيوتيّ:

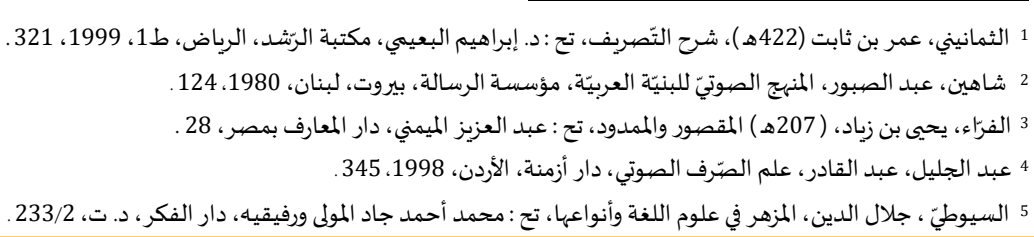




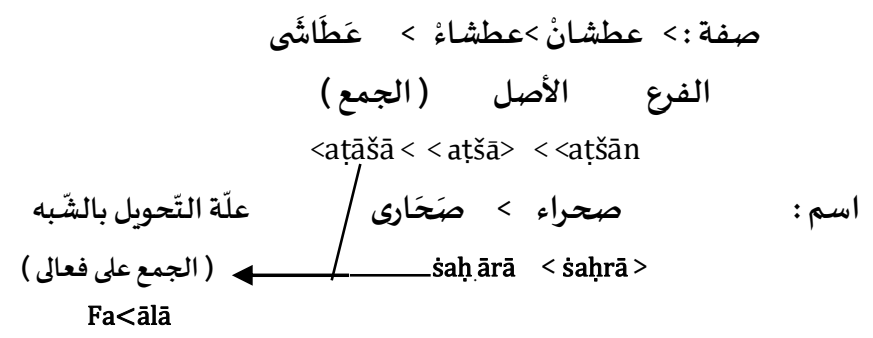

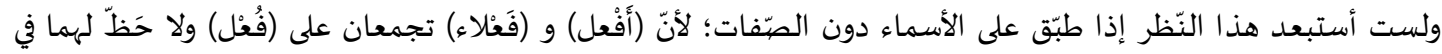

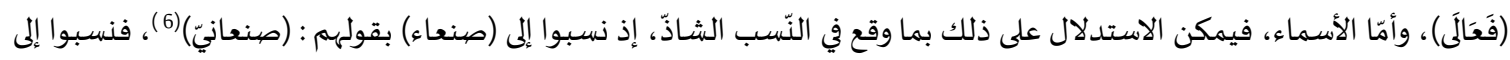

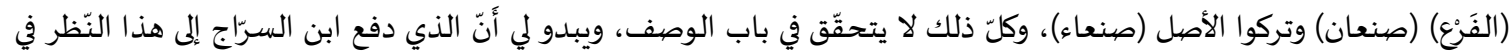

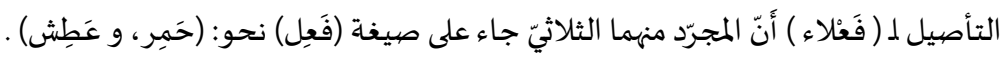

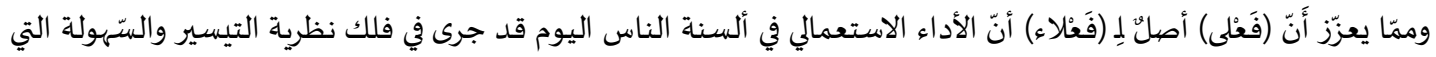

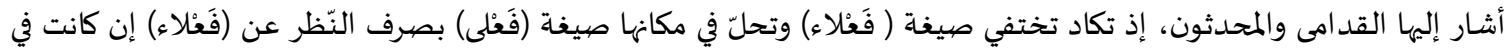

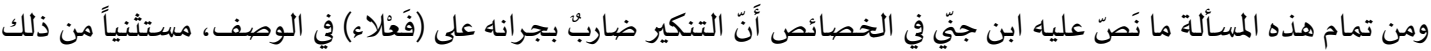

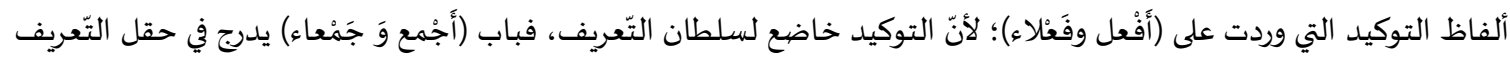

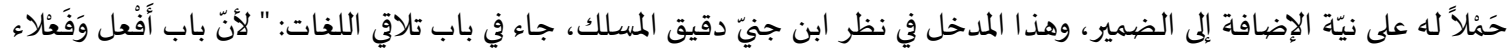

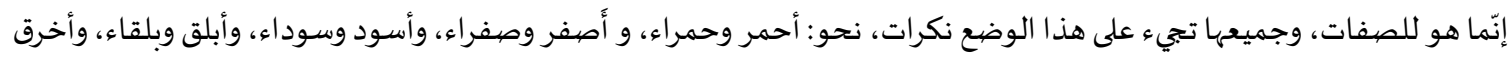
وَخَرْقاء وهذا كلّه صفات نكرات، فأمَّا أجمع وجمعاء ، فاسمان معرفتان، وليسا بصفتين، فإنِّما ذلك اتَّفاق وقع بين هذه الكلم المؤكّد

واشارة ابن جنّي فهيا نظر تأصيليّي بيّن يضاف إلى ما ذكر سابقاً؛ لَأَنَ التنكير أصل، والتعريف فَرْع، أمّا لام (فعلاء)، فقد يعترهها

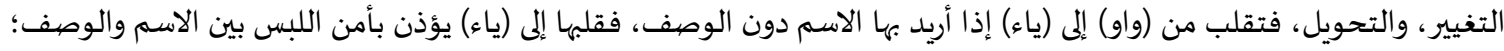

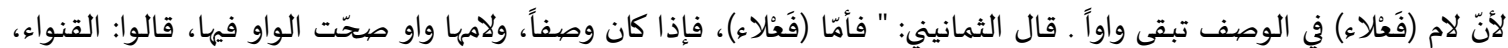
والعشواء، والعثواء ، فأمّا ( العلياء ) في قول الشاعر:

\section{ألا يا بيتُ بالعلياء (8)}

فليس بتأنيث الأعلى كما قالوا: أحمر وحمراء؛ لأنّ تأنيث الأعلى العُلْيا، كما قالوا : الأفضل والفُضْلى، فقلبوا واو العلياء ياء كما

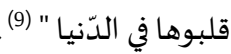

\section{المبحث الثاني: المسوّّغات}

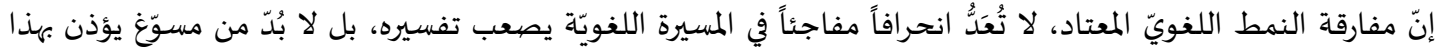

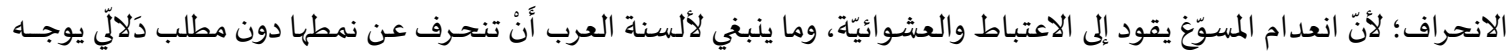

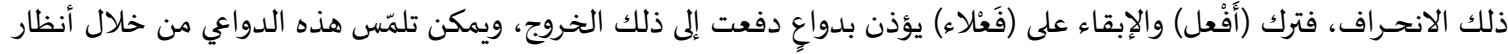
التصريفييّن في المدوّنة التصريفيّة، واللغويّين، ويمكن ردّ ذلك إلى الإن:

6 سقّال، ديزيره، الصَّرف وعلم الأصهوات، دار الصيّداقة العربيّة، بيروت، لبنان، ط1، 1996، 192، 105

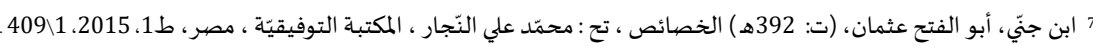

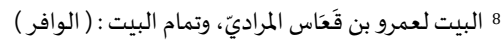

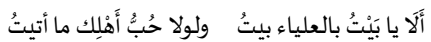

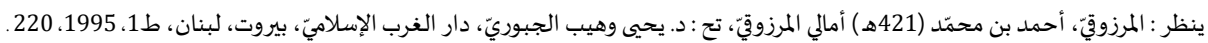

9 


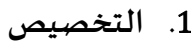

إنّ المقابل الضديّ للتخصيص العموم أو التعميم، وقد حدّ ابن فارس هذين المصططلحين بقوله: " والعام الذي يأتي على الجملة

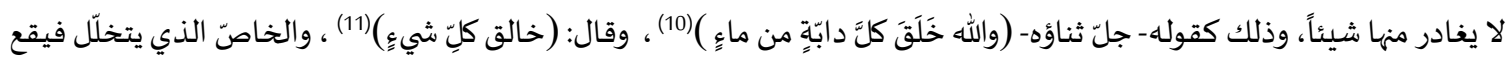

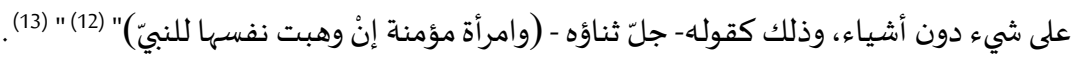

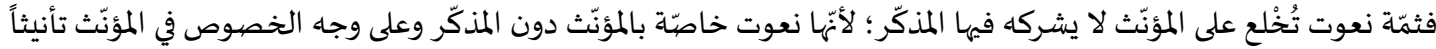

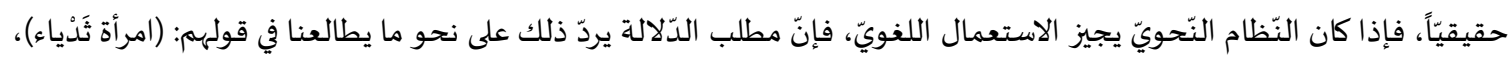

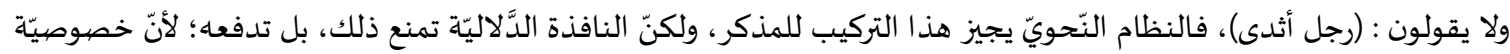

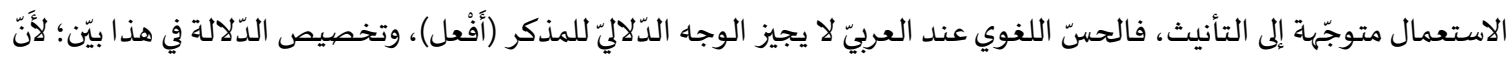

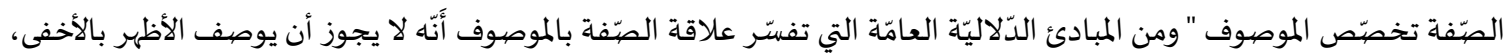

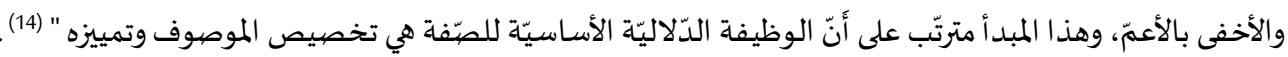

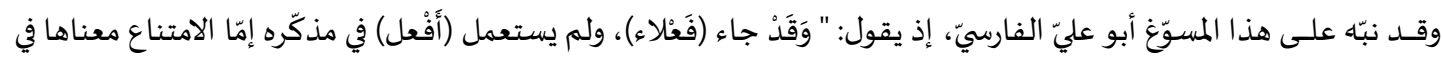

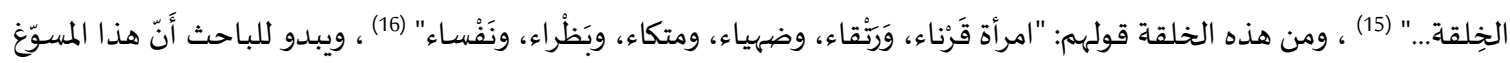

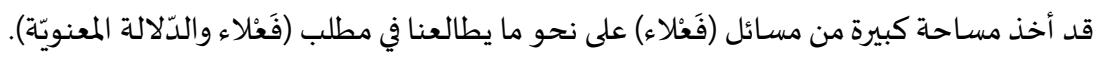

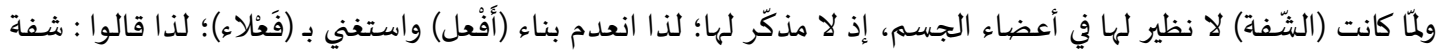
ظمياء (17) ، وَلثثة ظمياء.

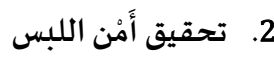

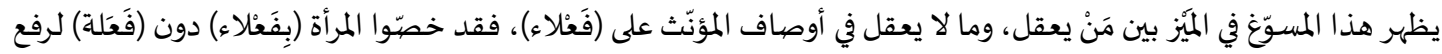

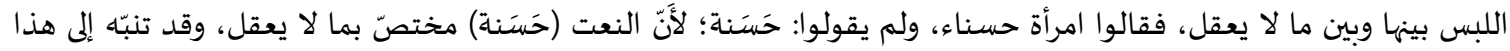

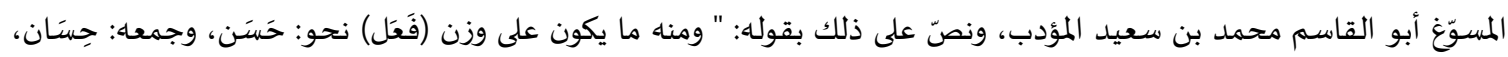

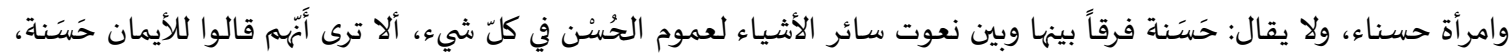

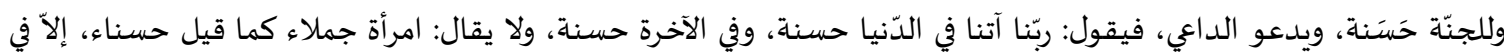
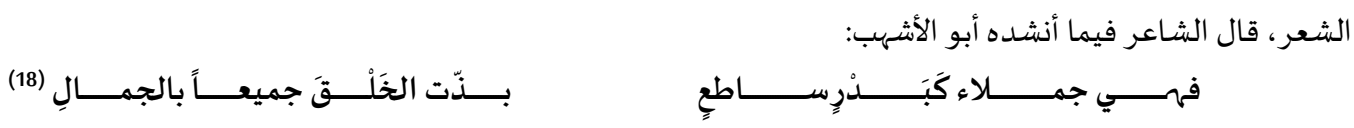

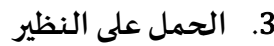

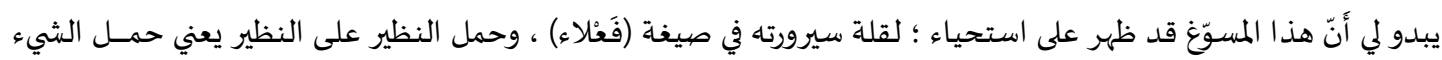

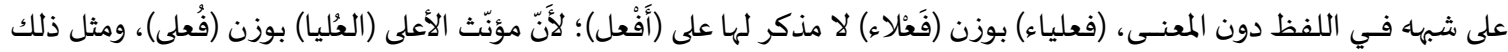

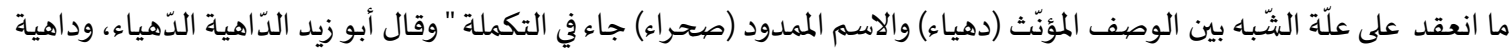

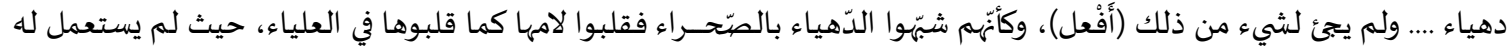




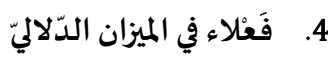

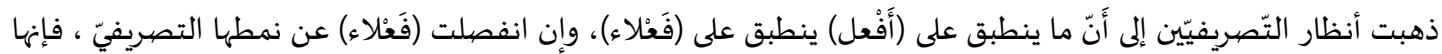

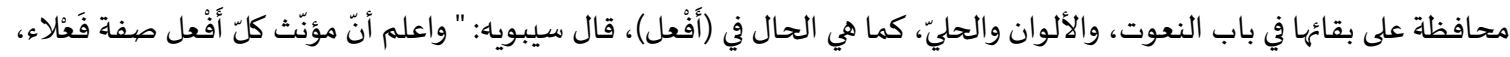

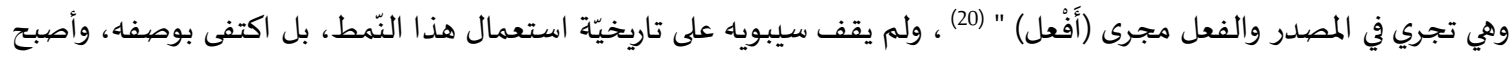

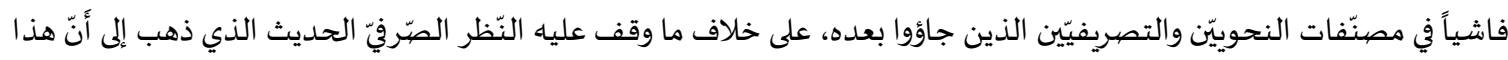

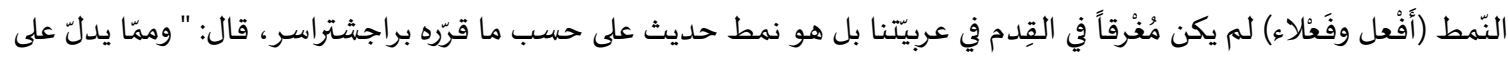

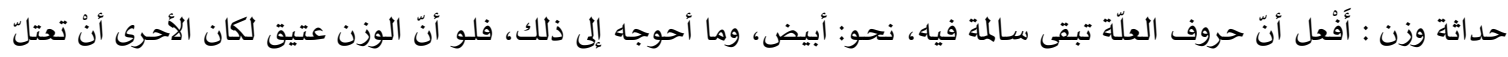

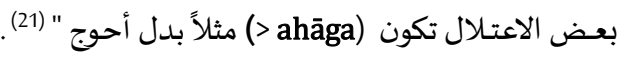

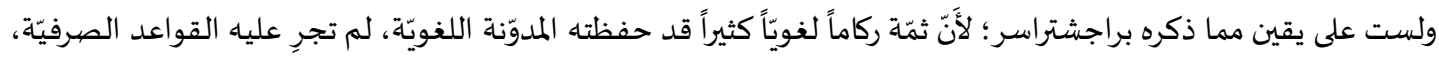

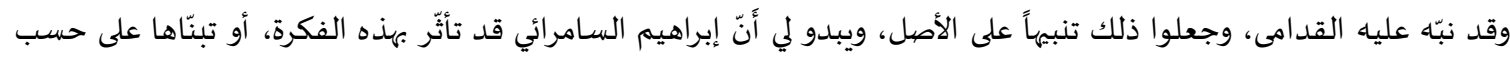

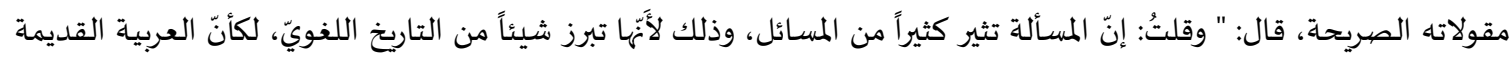

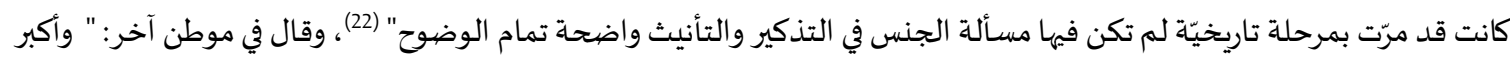

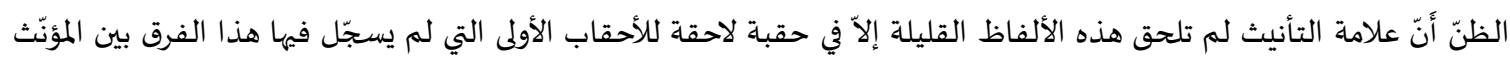

والمذكّر" (23)

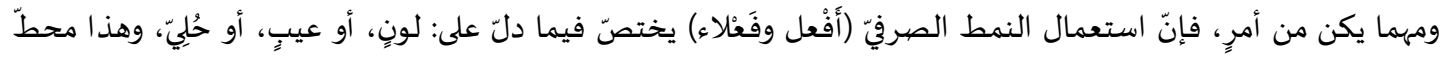

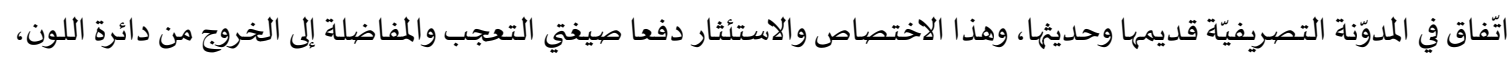

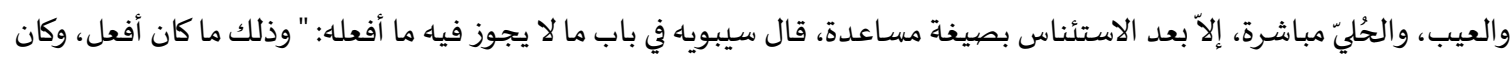

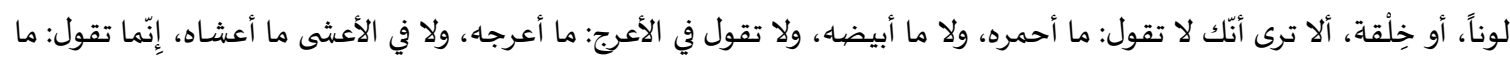

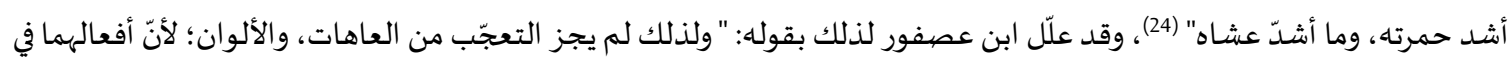

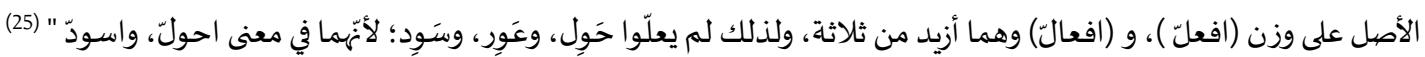

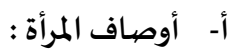

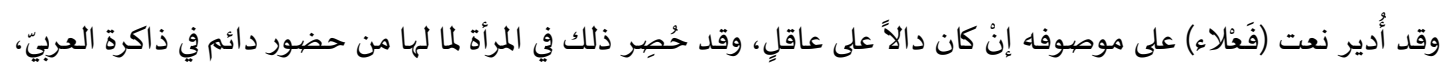

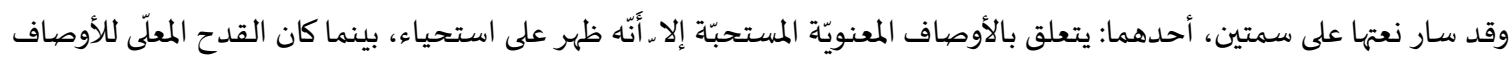

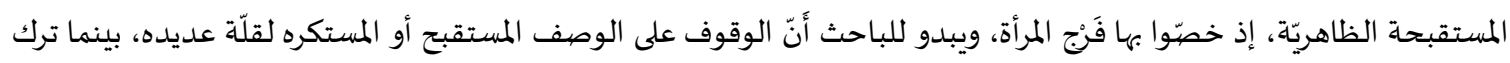

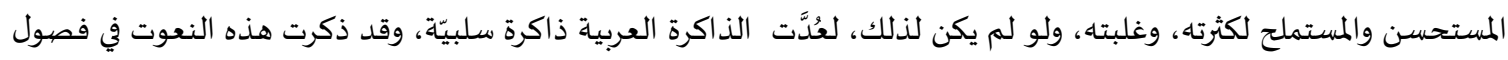

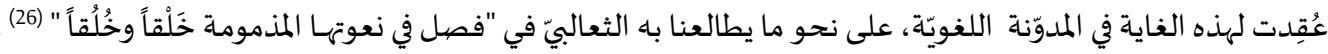

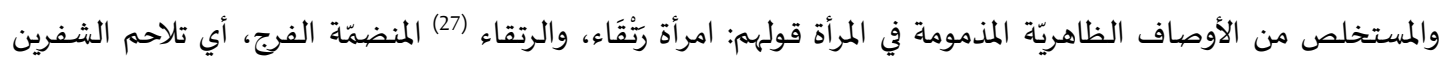

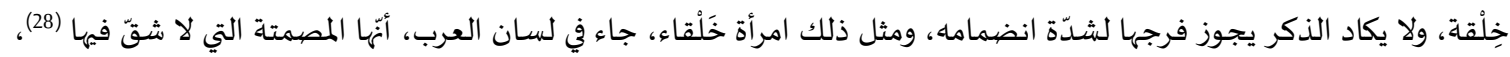

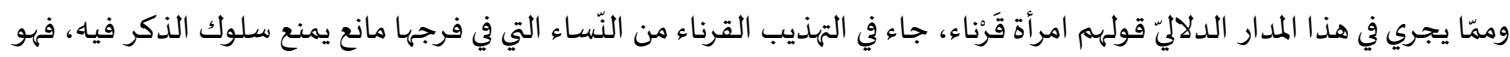
شيء يمنع الوطء ، وهو أحد عيوب المرأة في النكاح (29) .

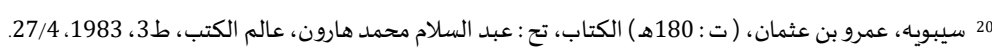

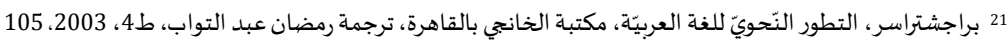

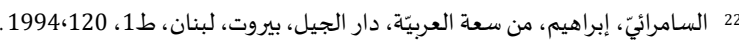
23 السامرائي، من سعة العربيّة، 121. 24 سيبويه، الكتاب، 97/4

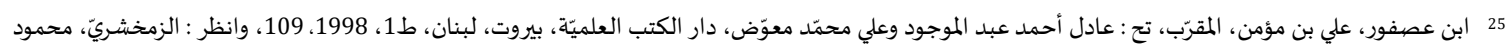

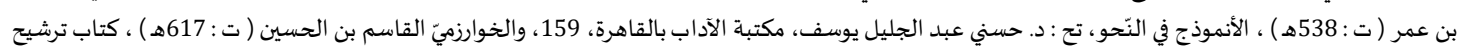

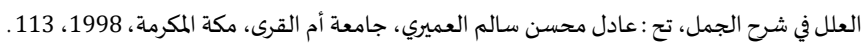

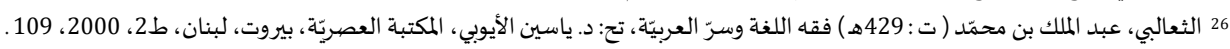

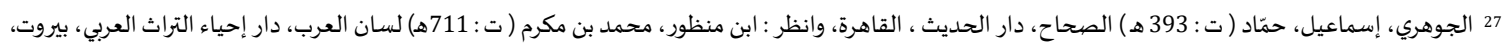

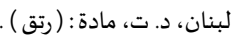

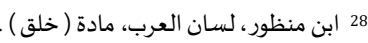

29 الأزهريّ، محمد بن أحمد ( ت : 370 3ه ) تهذيب اللغة، تح : محمد عوض مرعب، دار إحياء التراث العربي، بيروت، لبنان، ط1، مادة ( قرن ) . 


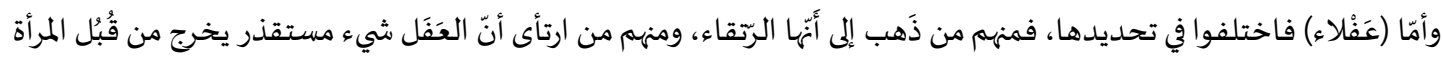

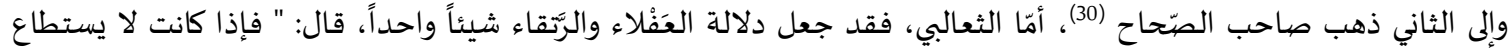

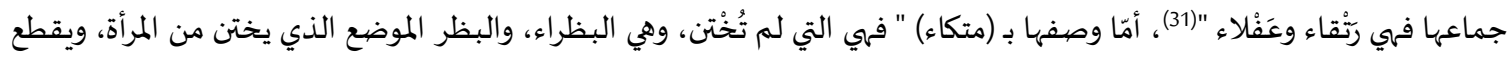

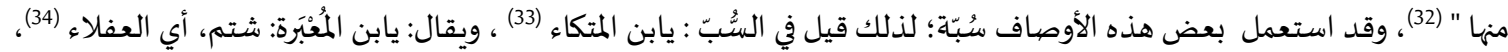

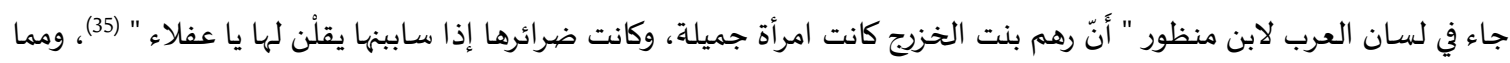

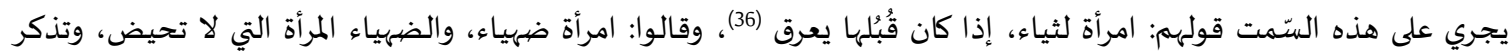

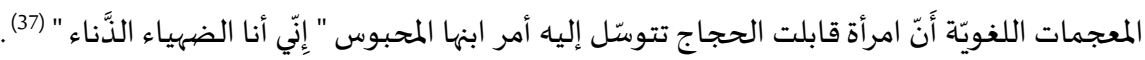

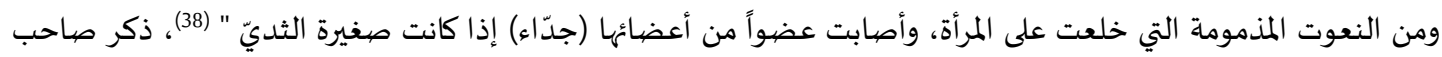

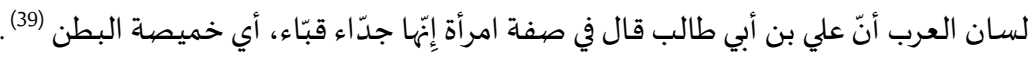

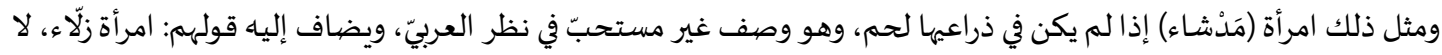

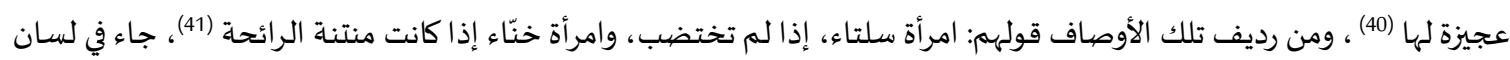

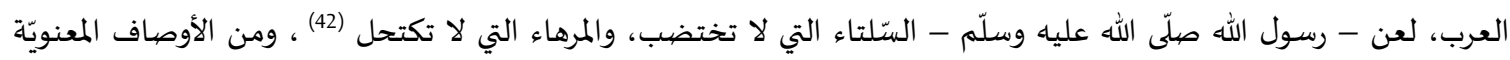

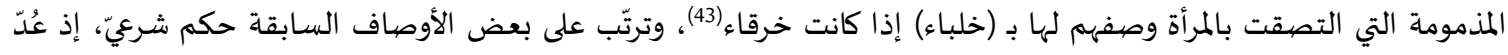

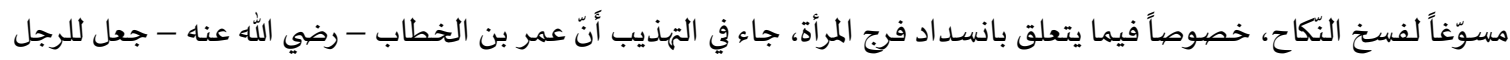

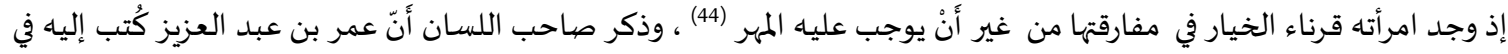

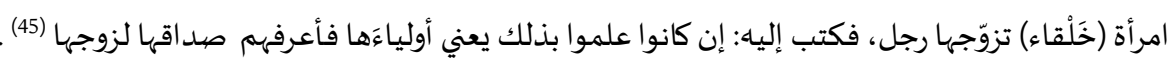

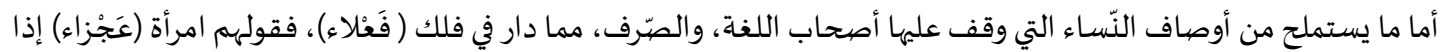

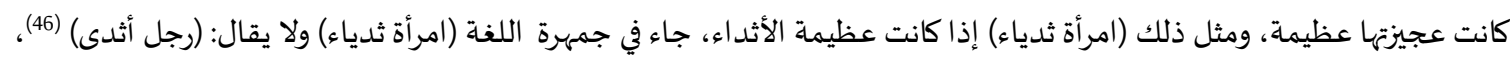

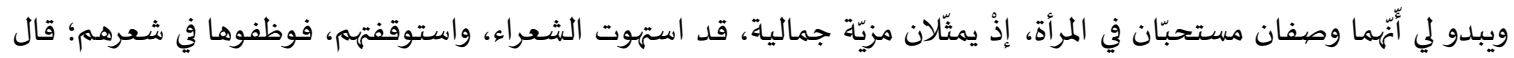
عنترة (47) (الكامل) المهان

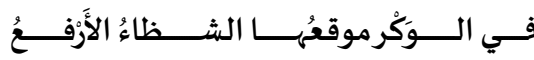

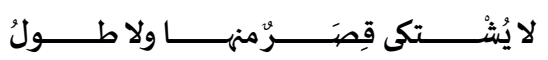

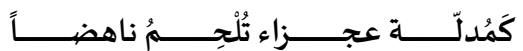

وقال كعب بن زهير (48) : ( البسيط )

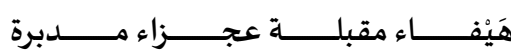

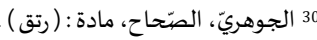

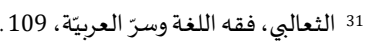

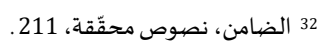

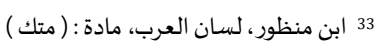

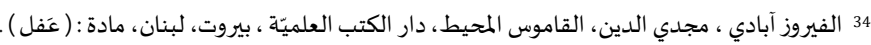

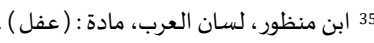
36 ابن منظور، لسان العرب، مادة : (لثي ) . وانظر : الفيروز آبادي ، القاموس المحيط.

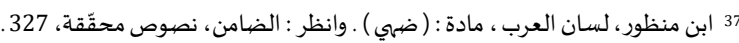

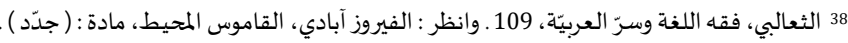

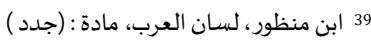
40 الثعالبي، فقه اللغة وسرّ العربيّة، 109.

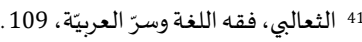

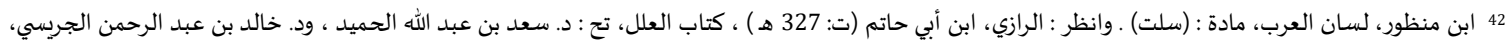

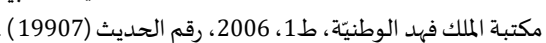

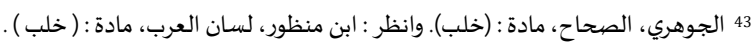

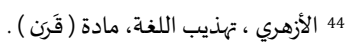

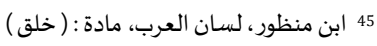

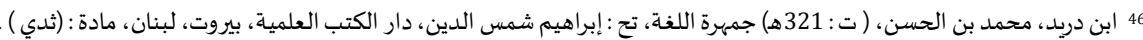

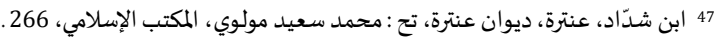

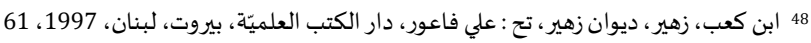


وقال معن بن أوس(49): ( الطويل)

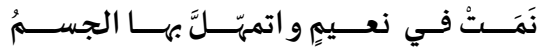

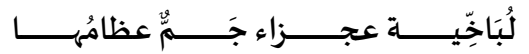

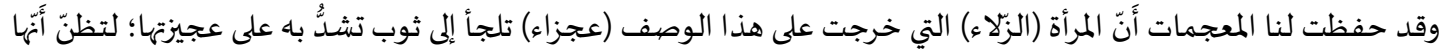

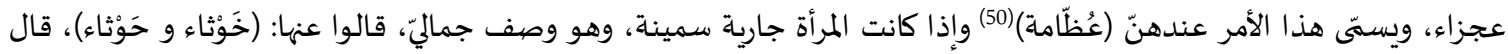

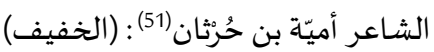
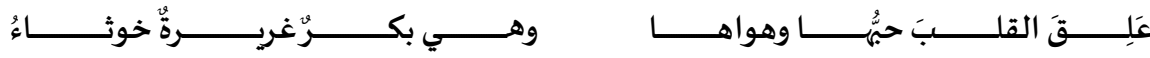

أمّا (ظميـاء) فهو وصـف مستحبّ يلامس شـفة المرأة، إذ تضـرب إلى لون السمرة، وقـد تطلق (ضـمياء) على (اللثة)(52) ، ولا نعـدم أَنْ

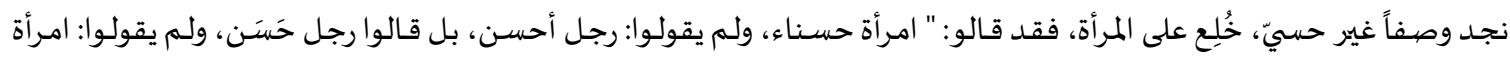
حسنة " (53) حجد وهنان

ب- أوصياف الناقة: من طريف ما نقل في هذه المسألة أنّ الثعالبي في باب الإبل نقل عن المبرّد قوله: " الناقة بمنزلة المرأة ، والبعير بمنزلة الإنسان "

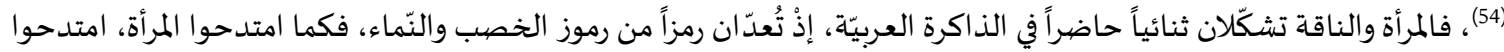

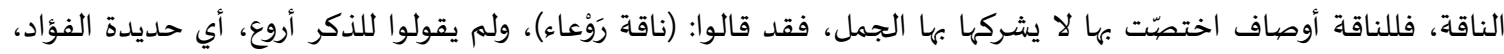

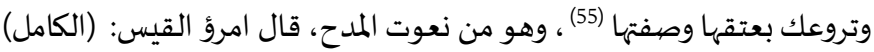

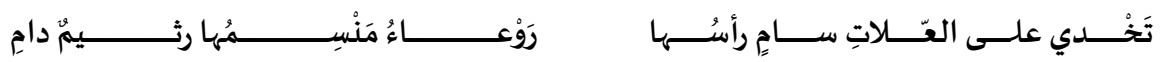

وقال حميد بن ثور (56) : (الطويل)<smiles>[14CH3][14CH2][14CH2][14CH2][AlH2]</smiles>

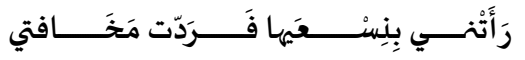

وممّا يستحسن في النّاقة ( القَرْو )، وهو طول السّنام، جاء في الصحاح : ناقة قرواء طويلة السيّنام ، ولا تقل : جمل أَقْرَى (57) ، قال رؤبة بن العجاج (58) : (الرجز)

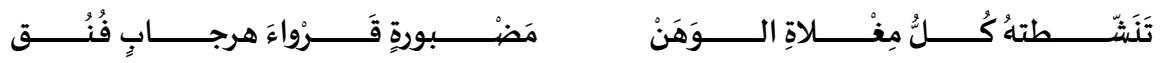
ويضياف إلى هذا قولههم : ( ناقة سَجْواءَ) إذا حُلِبَت سَكَنت، قال الشَاعر (59): (الطويل)

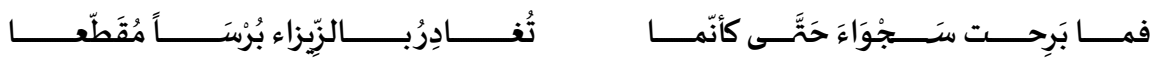

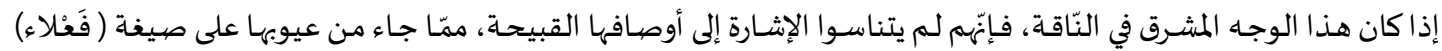

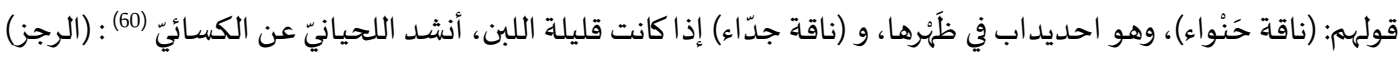

49 أوس، معن بن، ديوان معن بن أوس، تح : د. نوري حمودي القيسي، و د. حاتم الضامن، مطبعة دار الجاحظ، بغداد، 35 .

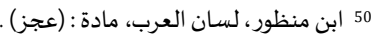

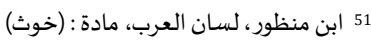
52

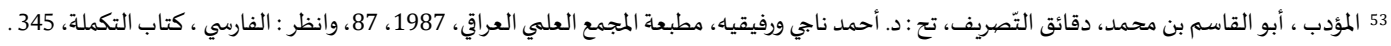
54 الثعالبي، فقه اللغة وسرّ العربيّة، 54. 55 امرؤ القيس، جندح بن حجر، الدّيوان، تح : محمد أبو الفضل إبراهيم، الفئ، دار المعارف، 1984، 1984، 116.

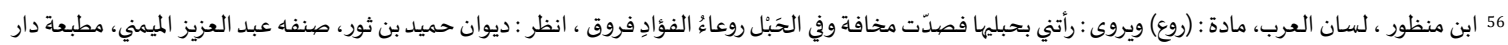

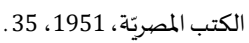

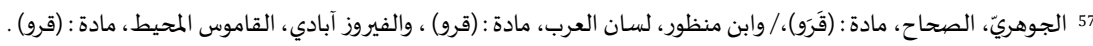

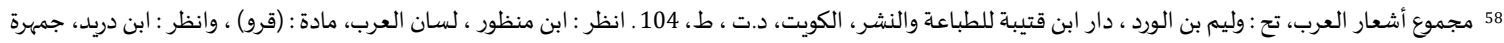
اللغة ، مادة : (قرو)

59 ينسب إلى الراعي النميريّ، ديوان الرأي النميري، شرح د. واضح الصمد، دار الجيل، بيروت، ط1، 1995، 273، انظر : ابن منظور ، لسان العرب، مادة (سجو) . 


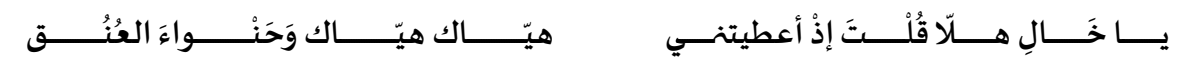

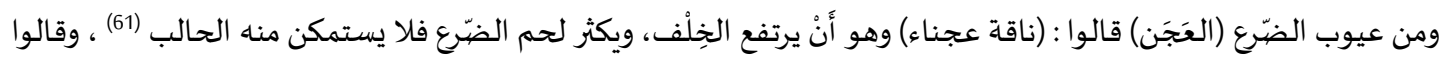

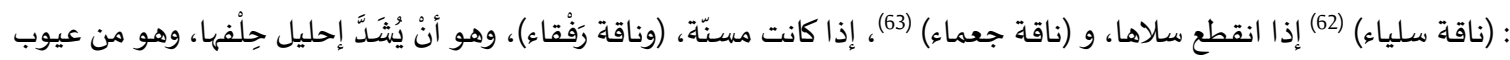

الإناث (64) (نافياً)

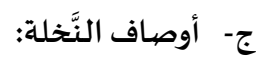
جاء في نعت النخلة التي تحمل سنة، وتتأخر أخرى، قولهه: (نخلة سَنْهاء) ذكر ذلك أبو حاتم السجستاني في (باب النّخلة)، وأنشد قول سويد بن الصيّامت (65) : (الطويل)

ولكـــن عر ايسـا فــي الســنين الجـــو ائح

على لِيْنَة سَوْوقاء تَنْفُو فُنُونها

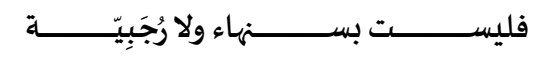

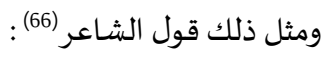

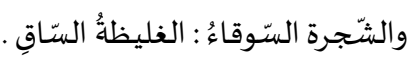

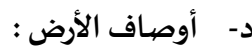

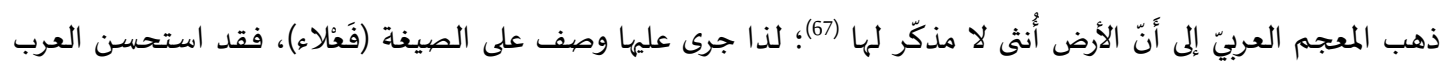

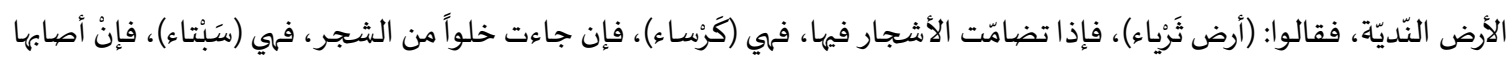

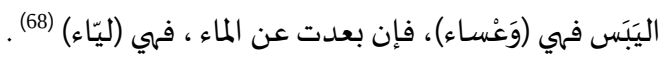

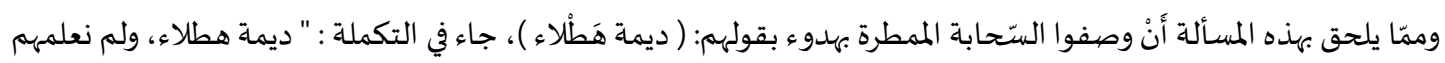
قالوا : مطر أهطل " (69)، وأنشد المعجم على ذلك بلى بيت امرئ القيس (70): (الرمل)

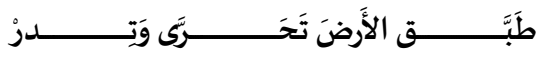

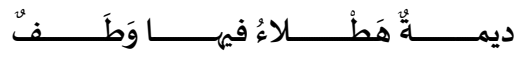

هـ - أوصاف الحرب ومتعلقاتها

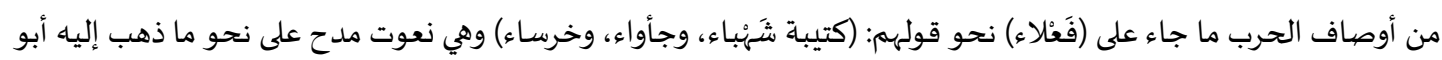

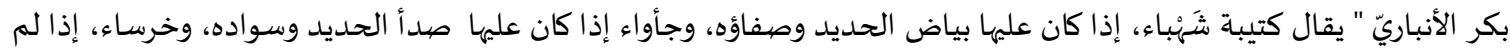
يسمع لها صوت من كثرة الحديد " (71).

60 ابن منظور، لسان العرب، مادة : ( حَنَو ) .

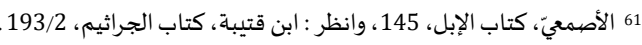

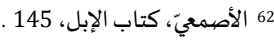

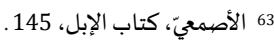

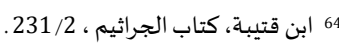

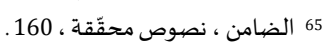

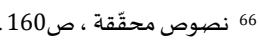

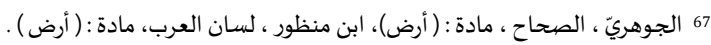

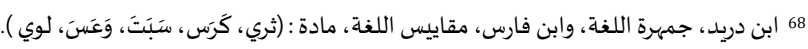

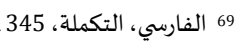
70 ابن منظور، لسان العرب، والفيروز آبادي، القاموس المحيط، مادة : ( هطل) ) ، وانظر : ديوان امرؤ القيس بعناية ابن دريد ، جمهرة اللفة، تح : عبد الرحمن المصطاوي، دار

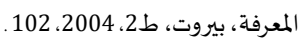
71 ابن الأنباريّ ، أبو بكر ، كتاب المذكّر والمؤنتّ، تح : د. محمّد عبد الخالق عضيمة، لجنة إحياء التراث، القاهرة، 1981، 262 
ومن مستلزمات الحرب الدّرع والقوس، وكلاهما مؤنّث لا مذكّر لله؛ لذا فوصفههما يكون على صيغة (فَعْلاء) دون (أَفْعل)، فإذاذا

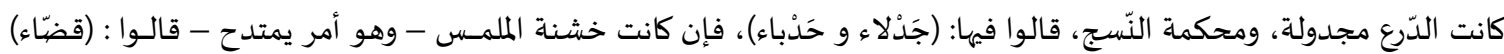
قال الحطيئة (72) (البسيط)

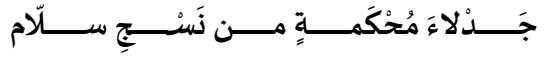

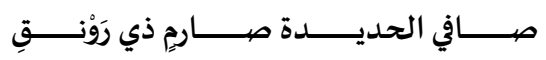

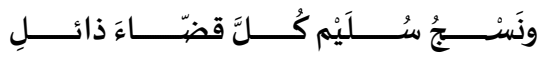

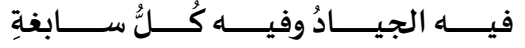

وقال كعب بن مالك (73) : (الكامل)

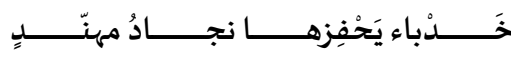

وقال النابغة (74) (الطويل)

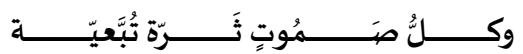

وَمُدِحت القوس إذا كانت غليظة تقي الفارس وتحميه، بقولهم : (قَوْنس كَبْداء )، قال الإسكافيّ : "وكَبِدها ما بين طرفي العِلاقة "

أمّا الثوب الخشن، فقالوا فيه: (حُلّة شَّوكاء)، ولم يقولوا : ثوب أَشْوك، وقد اعتذر الأصمعي من معرفة (شوكاء) ، وفسّرها أبو

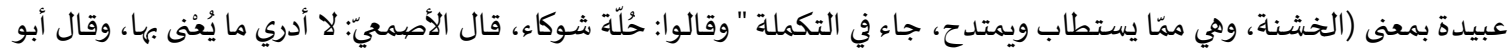

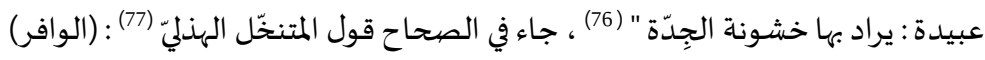

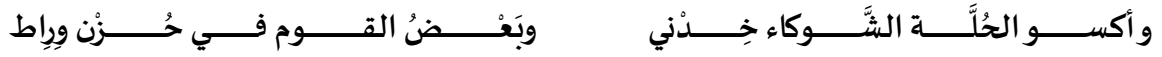

ومن متعلقات الحـرب (الغَارة)، وتغنـدو مَدْحاً إنْ كانت فاشية متفرِّة؛؛ لذا وصِفوها بـ (شَعْواء) فقالوا: (غارة شعواء)، أنشـد ابن الأعرابيّ (78) : (الرّجز) منعات التحن)

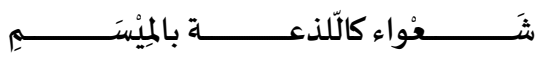

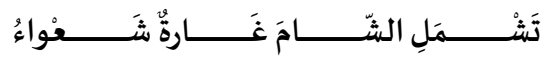

وممّا تُحْمد فياه الغارة إذا كانت في ليلة مضيئة، وقد عبّروا عنها بقولههم : (ليلة ضَحْياء، ولم يقولوا: نهارٌ أضحى) (80).

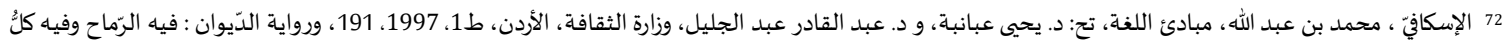

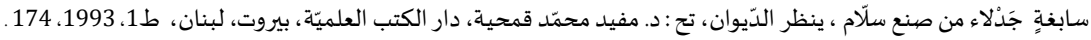

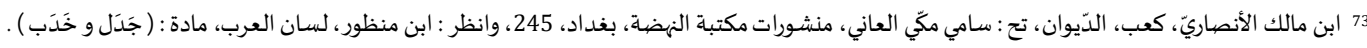

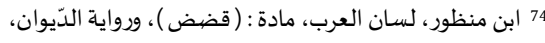

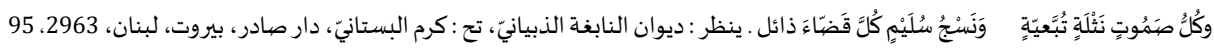

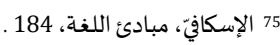

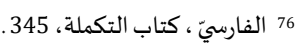

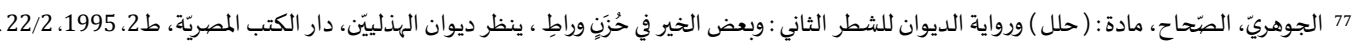

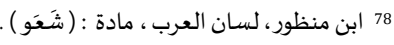

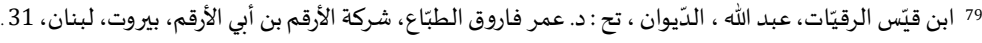

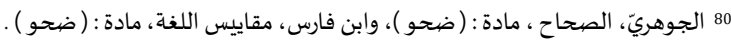


المبحث الثالث: نتائج الدراسة

وممّا توفّرت عليه نتائج هذه الدراسة:

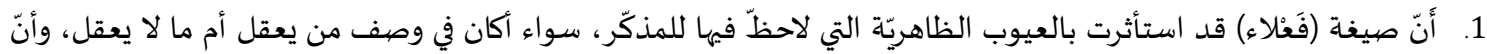

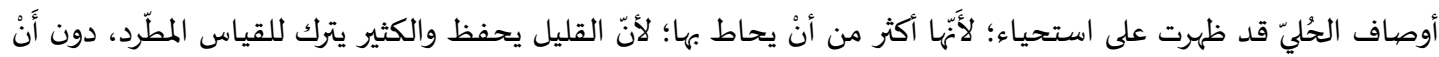

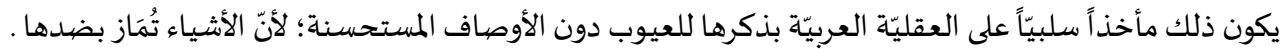

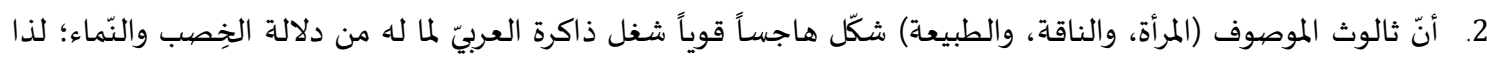

استأثرت نعوتها بمسائل صيغة (فَمَّلاء) .

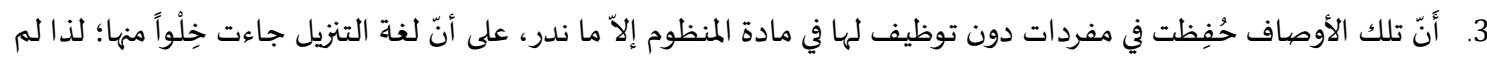

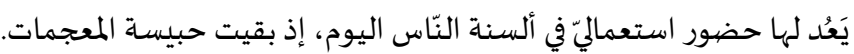

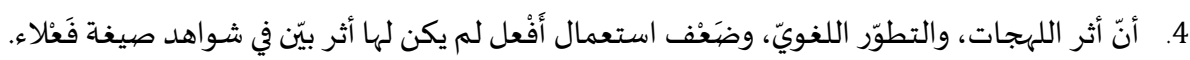

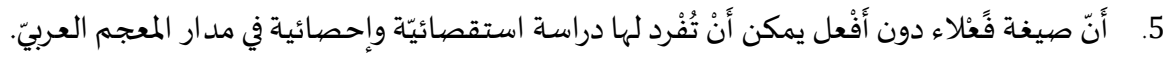

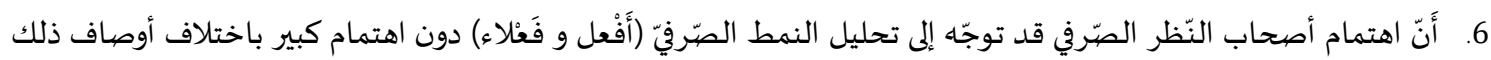

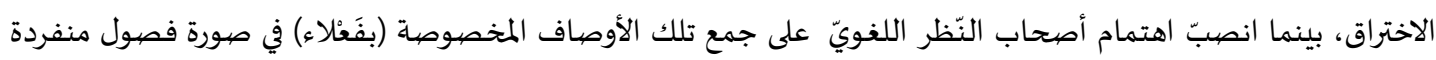

بذكر دون تحليل.

المراجح:

1. الأزهريّ محمد بن أحمد. تهذيب اللغة. تح : محمد عوض مرعب، دار إحياء التراث العربيّ، بيروت، لبنان، ط11.

2.

3.

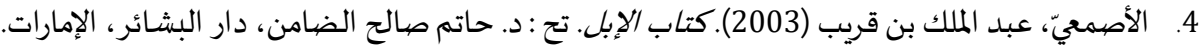

5.

6.

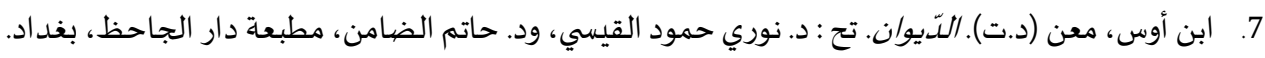

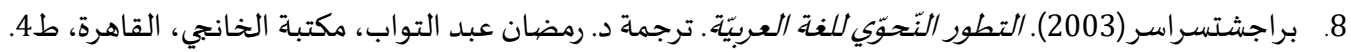

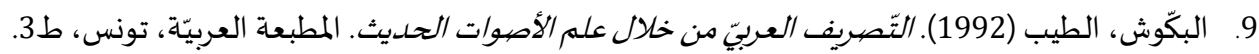

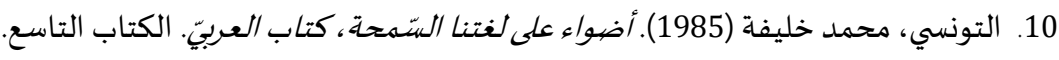

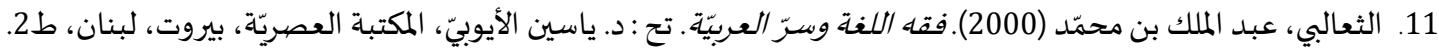

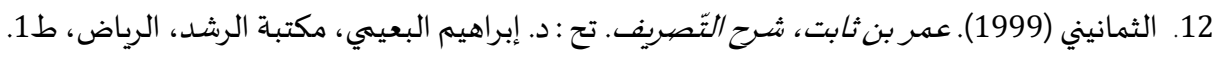

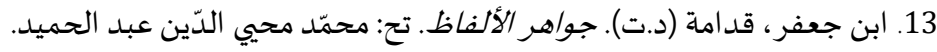

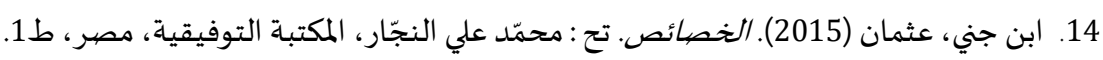

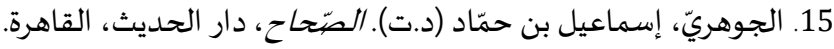

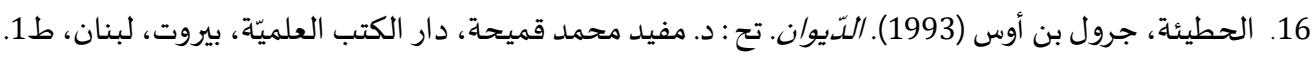

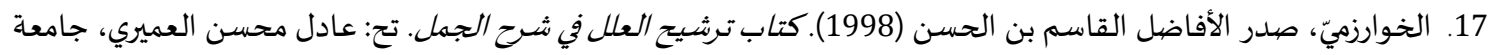

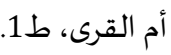

18. ابن دريد، محمد بن الحسن (د.ت). جمهرة اللغنة. تح : إبراهيم شمس الدّين ، دار الكتب العلميّة، بيروت، لبنان.

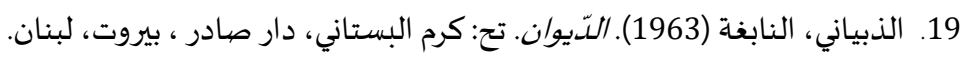

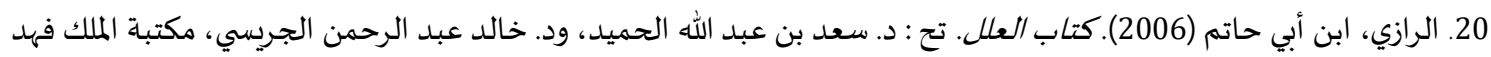

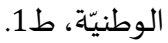

21. الزمخشريّ، محمود بن عمر (1417هـ). شُح الفصيح. تح: إبراهيم بن عبد الله الغامدي، جامعة أم القرى.

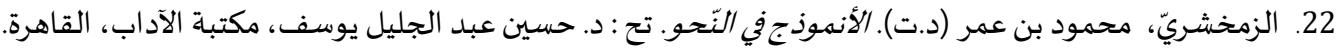

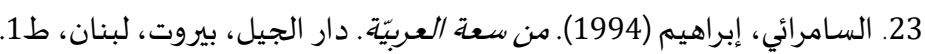


24. السامرائي، فاضل صالح (1980). معاني الأبنية في العبيّة. منشورات جامعة بغداد.

25. سقال، ديزيره (1996). الصّرف وعلم الأصهوات. دار الصيداقة العربيّة، بيروت، لبنان، ط1. 1.

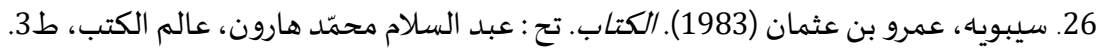

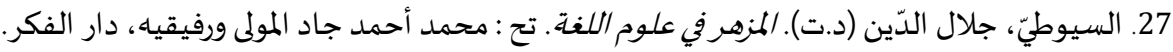

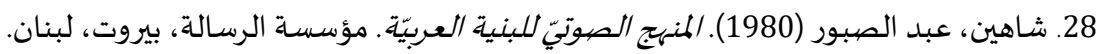

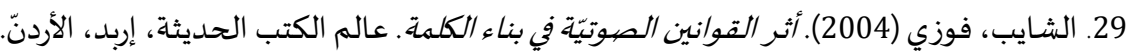

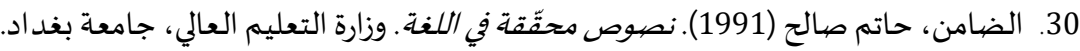
31. عبد الجليل، عبد القادر (1998). علم الصِّرف الصَّوتيّ. دار أزمنة، الأردن. 32. ابن عصفور، علي بن مؤمن (1998). المقرّب. تح : عادل أحمد عبد الموجود وعلي محمّد معوّض، دار الكتب العلميّة، بيروت، لبنان، طبن

33. ابن فارس، أحمد (د.ت). الصياحبي في فقه اللغة. تح : الستيد أحمد صقر، مطبعة عيسى البابي الحلبي وشركاه، القاهرة.

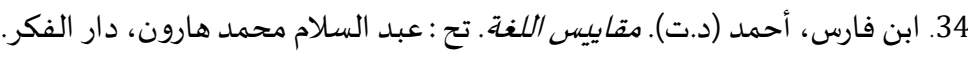

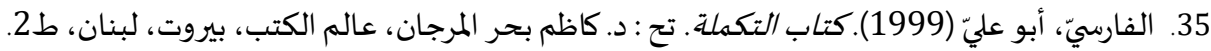

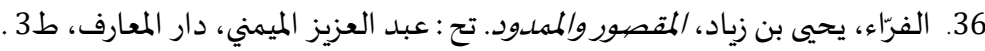

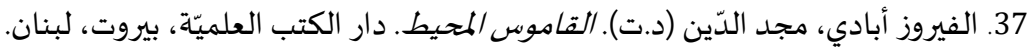

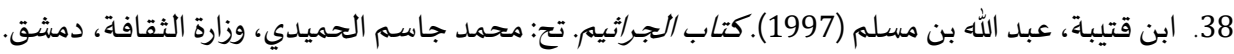

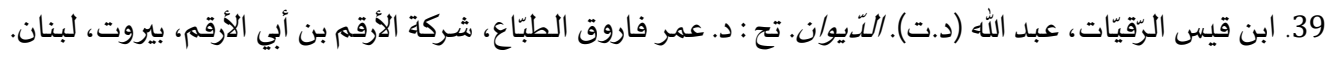

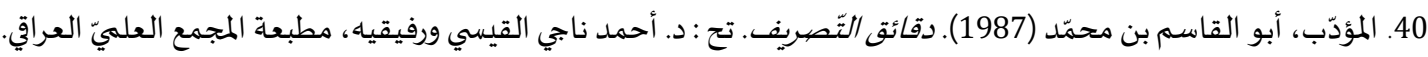

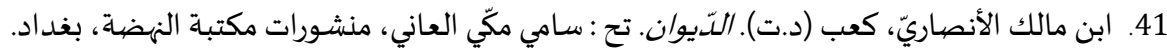

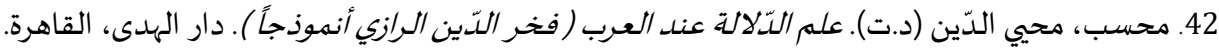

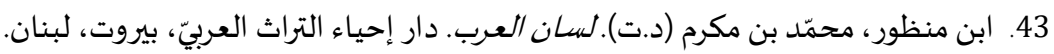

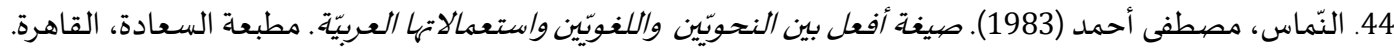

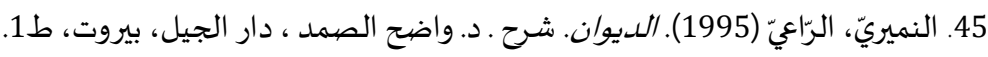


المجلة الدولية للدراسات اللغوية والأدبية العربية

International Journal for Arabic Linguistics and Literature Studies (JALLS)

www.refaad.com

Journal Homepage: https://www.refaad.com/views/JALS/home.aspx ISSN: 2663-5860(Online) 2663-5852(Print)

\title{
Dispensing with the formula of ( a $\mid>a f>$ ) - it's a formula of from the formula of ( $>\mathbf{a}>\mathrm{fa}$ ) in section of the qualifying adjective
}

\author{
Hussein Abbas Mahmoud Alrafaiah \\ Prof at Department of Arabic Language and Literature, Al- Hussein Bin Talal University, Jordan \\ drhussen948@yahoo.com
}

Received: 19/5/2021 Revised: 13/7/2021 Accepted: 16/8/2021 DOI : https://doi.org/10.31559/JALLS2021.3.3.2

\begin{abstract}
The morphological pattern used in the qualifying adjective requiring that the formula of $(\bar{a} \mid>a f>)$ to be a synonym of $(>\mid \mathrm{a}>\mathrm{fa})$ in terms of colors, defectives, and ornaments, which calumniate the differential value- according to the modern stylistic- that bring together the opposites in on concept, so these two formulas correlate, one of them is not mutually exclusive, but there is a breakthrough for this pattern, dispenses with a formula (>la $>\mathrm{fa})$, and the formula(ā $\mid>a f>)$ remains stand-alone with descriptions no portion for formula (>la $>$ fa) according to what the linguistic blog kept for us in general, ad morphological and syntactical particularly, so this research aims to establish the formula (âl>af $>$ ), identify the opinions of ancients and modernists, and the reasons of this breakthrough in the agreed pronunciations in linguistic and morphological blog without the different pronunciations in it, which is shown sometimes separately as (âa $>$ af $>)$ and at other times combined between $(>\mathrm{la}>\mathrm{fa})$ and $(\mathrm{a} \mid>\mathrm{a}>)$.
\end{abstract}

Keywords: Morphological pattern; Formula (âlat)); Justifications; Dispensing.

\section{References:}

1. Abn Aws, M'n (D.T). Aldywan. Th: D. Nwry Hmwd Alqysy, Wd. Hatm Aldamn, Mtb't Dar Aljahz, Bghdad.

2. Abn Dryd, Mhmd Bn Alhsn (D.T). Jmhrh Allghh. Th: Ebrahym Shms Aldyn, Dar Alktb Al'Imyh, Byrwt, Lbnan.

3. Abn J'fr, Qdamh (D.T). Jwahr Alalfaz. Th: Mhmd Mhyy Aldyn 'bd Alhmyd.

4. Abn Jny, 'thman (2015). Alkhsa's. Th: Mhmd 'ly Alnjar, Almktbh Altwfyqyh, Msr, T1.

5. Amr' Alqys (2004). Aldywan. Th: 'bd Alrhmn Almstawy, Dar Alm'rfh, Byrwt, Lbnan, T2.

6. Abn Alanbary, Abw Bkr (1981). Ktab Almdkr Walm'nth. Th: D. Mhmd 'bd Alkhalq 'dymh, Ljnh Ehya' Altrath, Alqahrh.

7. Alastrabady, Jmal Aldyn. Shrh Alshafyh. Th: Mhmd Nwr Alhsn Wrfaqh, Dar Alktb Al'emyh, Byrwt, Lbnan .

8. Alasm'y, 'bd Almlk Bn Qryb (2003). Ktab Alebl. Th: D. Hatm Salh Aldamn, Dar Albsha'r, Alemarat.

9. Alazhry Mhmd Bn Ahmd. Thdyb Allghh. Th: Mhmd 'wd Mr'b, Dar Ehya' Altrath Al'rby, Byrwt, Lbnan, T11.

10. Albkwsh, Altyb (1992). Altsryf Al'rby Mn Khlal 'Im Alaswat Alhdyth. Almtb'h Al'rbyh, Twns, T3.

11. Brajshtsrasr(2003). Alttwr Alnhwy Llghh Al'rbyh. Trjmh D. Rmdan 'bd Altwab, Mktbt Alkhanjy, Alqahrh, T4.

12. Aldamn, Hatm Salh (1991). Nsws Mhqqh Fy Allghh. Wzart Alt'lym Al'aly, Jam't Bghdad.

13. Aldbyany, Alnabghh (1963). Aldywan. Th: Krm Albstany, Dar Sadr, Byrwt, Lbnan.

14. Aleskafy, Mhmd Bn 'bd Allh (1997). Mbad'e Allghh. Th: D. Yhya 'Eanbh, W'ed Alqadr Alkhlyl, Wzart Althqafh, Alardn, T1. 
15. Alhty'h, Jrwl Bn Aws (1993). Aldywan. Th: D. Mfyd Mhmd Qmyhh, Dar Alktb Al'lmyh, Byrwt, Lbnan, T1.

16. Aljwhry, Esma'yl Bn Hmad (D.T). Alshah, Dar Alhdyth, Alqahrh.

17. Alkhwarzmy, Sdr Alafadl Alqasm Bn Alhsn (1998). Ktab Trshyh Al'll Fy Shrh Aljml. Th: 'adl Mhsn Al'myry, Jam't Am Alqra, T1.

18. Alrazy, Abn Aby Hatm (2006). Ktab Al'll. Th: D. S'd Bn 'bd Allh Alhmyd, Wd. Khald 'bd Alrhmn Aljrysy, Mktbt Almlk Fhd Alwtnyh, T1.

19. Alsamra'y, Ebrahym (1994). Mn S'h Al'rbyh. Dar Aljyl, Byrwt, Lbnan, T1.

20. Alsamra'ey, Fadl Salh (1980). M'eany Alabnyh Fy Al'rbyh. Mnshwrat Jam't Bghdad.

21. Shahyn, 'bd Alsbwr (1980). Almnhj Alswty Llbnyh Al'rbyh. M'sst Alrsalh, Byrwt, Lbnan.

22. Alshayb, Fwzy (2004). Athr Alqwanyn Alswtyh Fy Bna' Alklmh. 'alm Alktb Alhdythh, Erbd, Alardn.

23. Sqal, Dyzyrh (1996). Alsrf W'Im Alaswat. Dar Alsdaqh Al'rbyh, Byrwt, Lbnan, T1.

24. Sybwyh, 'mrw Bn 'thman (1983). Alktab. Th: 'bd Alslam Mhmd Harwn, 'alm Alktb, T3.

25. Alsywty, Jlal Aldyn (D.T). Almzhr Fy 'lwm Allghh. Th: Mhmd Ahmd Jad Almwla Wrfyqyh, Dar Alfkr.

26. Altwnsy, Mhmd Khlyfh (1985). Adwa' 'la Lghtna Alsmhh, Ktab Al'rby. Alktab Altas'.

27. Alth'alby, 'bd Almlk Bn Mhmd (2000). Fqh Allghh Wsr Al'rbyh. Th: D. Yasyn Alaywby, Almktbh Al'sryh, Byrwt, Lbnan, T2.

28. Althmanyny (1999). 'mr Bn Thabt, Shrh Altsryf. Th: D. Ebrahym Alb'ymy, Mktbh Alrshd, Alryad, T1.

29. Alzmkhshry, Mhmwd Bn 'mr (1417h). Shrh Alfsyh. Th: Ebrahym Bn 'bd Allh Alghamdy, Jam't Am Alqra.

30. Alzmkhshry, Mhmwd Bn 'mr (D.T). Alanmwdj Fy Alnhw. Th: D. Hsyn 'bd Aljlyl Ywsf, Mktbt Aladab, Alqahrh. 